\title{
Vibration control method for a crawler-type combine harvester
}

\author{
Xueliang Zhang ${ }^{1,2 *}$, Kuandong Peng ${ }^{2}$ \\ ${ }^{1}$ School of Mechanical \& Electrical Engineering, Hangzhou Polytechnic, Hangzhou 311402, China, ${ }^{2}$ College of Mechanical Engineering, \\ Zhejiang University of Technology, Hangzhou 310023, China"
}

\author{
A B S TR A C T
}

\begin{abstract}
The traditional vibration control method for the crawler-type combine harvester based on experience is only a small piece of weight iron added to the main drive shaft of the cutter, and the mass of the weight iron is determined by the technician with experience, so the vibration control effect is not obvious. Therefore, a vibration control method for the new crawler-type combined harvester is put forward in this paper. The engine and cutting structure are the main sources of the crawler-type combine. According to the force analysis results of the cutting structure and the results of structural dynamics analysis, each acting force and moment of force are obtained, and the optimal combination scheme for calculating the position and mass of weight distribution is calculated to solve the cutting structure's vibration of the crawler-type combine harvester. According to the vibration theory and modern design method, the vibration control of the crawler-type combine harvester engine is realized through the model analysis and the finite element calculation to establish the vibration damping model and design the parameters of the damping cushion. The experimental results show that the proposed method can effectively improve the vibration status of crawler-type combine harvesters, and the vibration level of harvesters is reduced by $50 \%$ to $80 \%$ in field operation.
\end{abstract}

Keywords: Crawler-type combine harvester; Cutting structure; Engine; Damping pad; Conductivity; Vibration control

\section{INTRODUCTION}

The output value of agricultural economy is increasing day by day, and the modernization of machinery is developing at a high speed. The use and promotion of agricultural machinery make the heavy farm work transformed from manpower to mechanization, which greatly reduces the workload of farmers' hard work in the field (Tang et al., 2014). With the development of agricultural mechanization to more efficient and more convenient direction, agricultural machinery has been warmly welcomed by the masses of farmers (Amereh et al., 2018; Krauklis and Dreyer, 2018; Rafiee et al., 2017; Sandhu et al., 2018; Sautrot-Ba et al., 2018; Troujeni et al., 2018). The market prospect is very considerable, and it has further promoted the development of agricultural mechanization. In China's annual total grain output, the output of rice and wheat is more than half of the total output, and its planting area is all over the country. It is the two of the most important grain product in China. Because the harvest of wheat and rice mainly depends on the combine harvester, it decides the pivotal position of the combine harvester in the field of agricultural machinery, which makes the production scale expanded year by year (Chen et al., 2017). As a large and complex agricultural machinery, the combined harvester has the characteristics of heavy workload, strong operation continuity and bad working environment. The engine vibration has a certain influence on the reliability of the whole machine, resulting in the forced vibration of the host system and the interference of the machine's normal operation of. On the one hand, compared with the ordinary vehicle drivers, the cab base of the combine harvester is an important structure to support the driving table, which will transfer the vibration of the internal machinery produced by the engine of the harvester and the road excitation to the driving seat. Therefore, the driver of the combine harvester is more likely to produce fatigue. On the other hand, it causes residual deformation and cracks, accelerates mechanical aging failure and reduces the service life (Ghaderi et al., 2014). The users are more and more demanding for the high quality and function of the crawler-type combine harvester. It is urgent to find an effective method to reduce the vibration of the crawler-type combine and determine the vibration damping measures (Garcia et al., 2017; Shen et al., 2017; Xie et al., 2018).

\footnotetext{
${ }^{*}$ Corresponding author:

Xueliang Zhang, School of Electrical and Mechanical Engineering, Hangzhou Polytechnic, Hangzhou, 311402, China. E-mail: heroszxl@163.com

Revised: 09 January 2018; $\quad$ Accepted: 05 October 2018
} 
Engine and cutting structure are the main vibration sources of crawler-type combine harvester (Polin et al., 2014). The cutting structure of the crawler-type combine harvester belongs to the support cutting, the fixed blade is stable, but the moving blade is cut at a certain speed, and the speed of the cutter's motion directly affects the cutting quality. As the moving blade travels in the reciprocating motion, it is bound to have a constant change of acceleration, and the structure is made up of components with a certain mass, which is bound to produce the inertia force of the reciprocating motion (Amponsah et al., 2017). The inertia force acts on the cutting platform and causes the continuous vibration of the cutting platform. Although the mass of the cutting platform can absorb part of the vibration, the vibration of the cutting platform is still serious (Ahamed et al., 2017; Roy et al., 2018; Zhang et al., 2018). In view of the above problems, the method of increasing the balance weight should be adopted to reduce the vibration degree, reduce the wear and brittle fracture of parts caused by the vibration, and improve the mechanical reliability and the working quality (Dong et al., 2017). The key to solve this problem is to determine the size and orientation of counterweight, and do dynamic research on the transmission system of cutter. For the vibration problem of the harvester engine, the vibration model for the engine system of the combine harvester is set up, the vibration theory is designed and the damping pad is selected to reduce the vibration effect produced by the engine (Daya and Pant, 2017)

\section{Vibration control method of crawler-type combine harvester \\ Analysis for vibration source of crawler-type combine harvester}

To solve the vibration problem of crawler-type combine harvester, it must first determine the main cause of vibration, that is, vibration source analysis. The vibration source analysis is the basis of dynamic analysis, and it is the basis for the vibration control of the crawler-type combine harvester, which is mainly based on the coherence of the excitation signal and the response signal as well as the interaction rate of density spectrum to judge (Jun et al., 2014). For a crawler-type combine harvester, the vibration of the engine, the working vibration of the cutting platform, the rotation of the roller, the motion of the vibrating screen and the unevenness of the ground all cause the vibration of the whole machine. When comparing the influence degrees of these working parts to the vibration of the harvester, it is necessary to separately test the vibration of a crawler-type combine harvester for engine idling, cutting work only, whole machine running but without walking and field working, in order to determine the main factor for the vibration of the crawler-type combine harvester (Sun et al., 2014). The normal working speed of the main shaft in the engine of most crawler-type combine harvester is about $1800 \mathrm{r} / \mathrm{min}$. Therefore, the vibration frequency of the engine is higher. The relative components of the engine are affected by its vibration, the alternating stress is formed in the local high stress area, and the fatigue crack is produced (Tang et al., 2014). The vibration is propagating rapidly on the support of the machine and affects the working environment. The mechanical model of vibration is described in Fig. 1. In general, the cutter drive shaft of a crawler-type combine harvester operates at the speed of $500 \mathrm{r} / \mathrm{min}$, its rotating inertia force, reciprocating inertia force, the vibration frequency and amplitude are all very large. The vibration directly acts on the frame and propagates on the frame (Maniam, et al., 2017).

Previous studies have shown that the vibration of cutting structure is the main cause of the vibration of harvesters, followed by engine transmission, and finally pavement roughness (Halim and Park 2014). But the working parts of the crawler-type combine harvester are too many. The vibration of the working parts, such as vibrating screen, detached roller and fan, need to be tested on the basis of the above analysis, and the larger vibration points of each part under different working conditions should be tested in detail. The test results show that the vibration of the transport trough and the threshing device mainly originates from the transmission shaft, while the vibration of the drum and the fan is mainly from the installation, and the vibration produced by itself is little (Litak et al., 2016). To sum up, the main vibration of the combine harvester comes from the cutting structure, the vibrating screen and the engine, moreover, the conveying tank, the threshing roller and the fan will also affect the vibration of the crawler-type combine harvester. The most influential factors are the engine and the cutting structure, thus, in this paper, the vibration of the cutting structure and the engine are studied and controlled.

\section{Vibration control method for cutting structure of crawler-type combine harvester The composition of the transmission structure in cutting platform}

The three parts of cutting, transporting and threshing are integrated to a crawler-type combine harvester, so as to achieve the effect of compact structure, light weight, small power consumption and small harvest loss. Cutting table, conveyor chain, cutting device, gripper, threshing machine, reeling wheel, conveying cage, etc. are shown in Fig. 2.

In Fig. 2, the number 1 represents the cutting platform for the crawler-type combine; 2 is the conveyor wheel; 3 is the cutting device; 4 is the gripper; 5 is the thresher; 6 is the pulley; 7 is the conveyor cage; 8 is the walking tractor. 8 is a walking tractor. 
Fig. 3 describes the transmission structure of the crawlertype combine harvester, which belongs to the crank rocker - sliding block structure. Analysis of Fig. 3 shows that the number 1 represents the cutter blade, 2 is the cutter, 3 is the connecting rod, and 4 is the crank. When the crank is evenly rotated, the cutter blade moves back and forth to complete the cutting task.

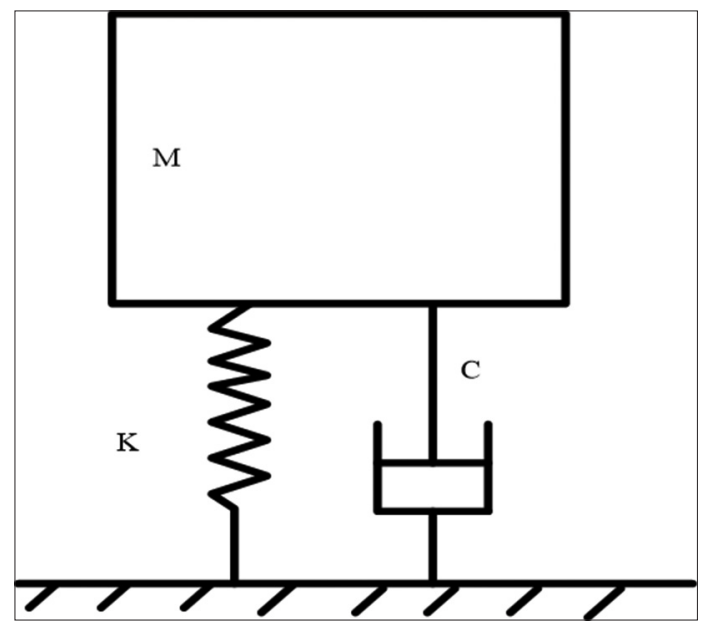

Fig 1. Vibration mechanics model.

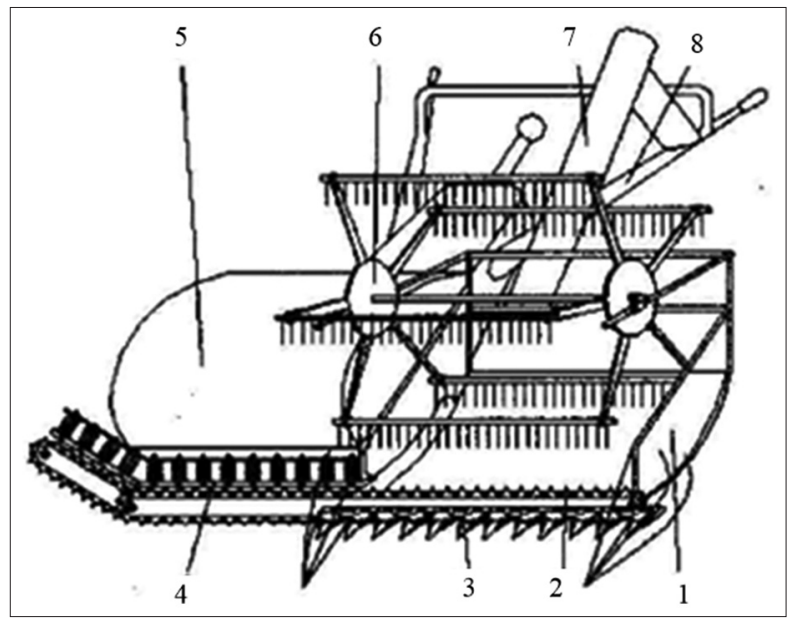

Fig 2. Structure diagram of a crawler-type combine harvester.

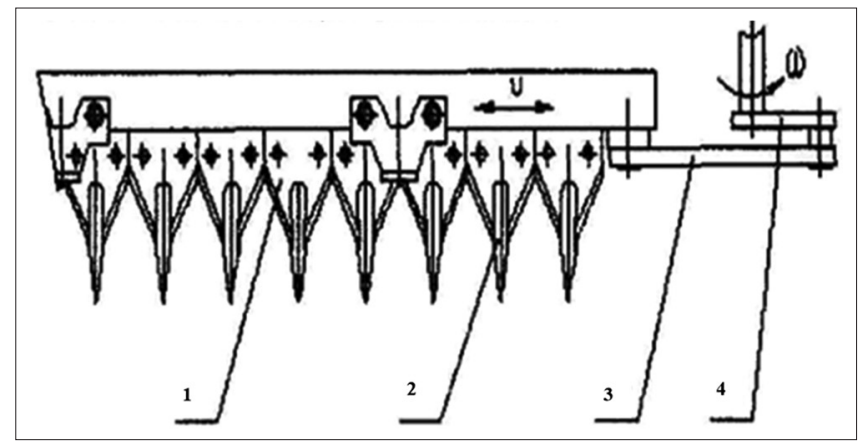

Fig 3. Reciprocating cutter in the transmission mechanism of the cutting platform.
The crank should rotate clockwise and the normal working speed is $550 \mathrm{r} / \mathrm{min}$. The connecting line of the two limit position in the rocker swing should pass the crank rotary center. This kind of transmission arrangement can make the average speed of the cutter reciprocating equal, and is favorable to the cutting tool transmission (Dorzhiev et al., 2015). The size of the swing angle of the rocker has a great influence on the acceleration of the cutter. When the other parameters are fixed, the greater the swing angle of the rocker is, the greater the acceleration of the cutter is, and the larger the vibration of the cutting platform is (Gafforelli et al., 2014), so the swing angle of the rocker should be controlled in a certain range.

\section{Force analysis of cutting structure}

As shown in Fig. 4, the cutting structure can be simplified as a crank slider structure. In the work, the high speed of the cutter is one of the important factors to ensure good cutting, but the increase of the cutting speed will cause the increase of the structure's inertia force, which leads to the severe vibration of the whole machine and cannot work normally ( $\mathrm{Li}$ et al., 2014). The way to reduce inertia force is to add a balance block at the other end of the crank, and the position and size of the balance block are the keys to reduce the vibration of the machine.

The variable should be satisfied the formula (1) in Fig. 4:

$\overrightarrow{O H}+\overrightarrow{A B}=\overrightarrow{O B}$

The above formula is transformed into analytical form and is described by formula (2):

$\left\{\begin{array}{l}x_{B}=x_{A}+L_{2} \cos \alpha_{2} \\ y_{B}=y_{A}+L_{2} \sin \alpha_{2}=-h\end{array}\right.$

$\sin \alpha_{2}=-\left(b+y_{A}\right) / L_{2}$ is obtained by the second term

of formula (2), that is, formula (3):

$\alpha_{2}=\arctan \left[\frac{b+y_{A}}{\sqrt{L_{2}^{2}-\left(b+y_{A}\right)^{2}}}\right]+\pi$

$\alpha_{2}$ is substituted into formula (2) to obtain $x_{B}$, and the second term of formula (2)is derived to get formula (4), (5) and (6):

$$
\begin{aligned}
& \dot{a_{2}}=\frac{-\dot{y}_{A}}{L_{2} \cos \alpha_{2}} \\
& \ddot{a}_{2}=\frac{-\ddot{y}_{A}+L_{2} a_{2}^{2} \sin a_{2}}{L_{2} \cos \alpha_{2}}
\end{aligned}
$$




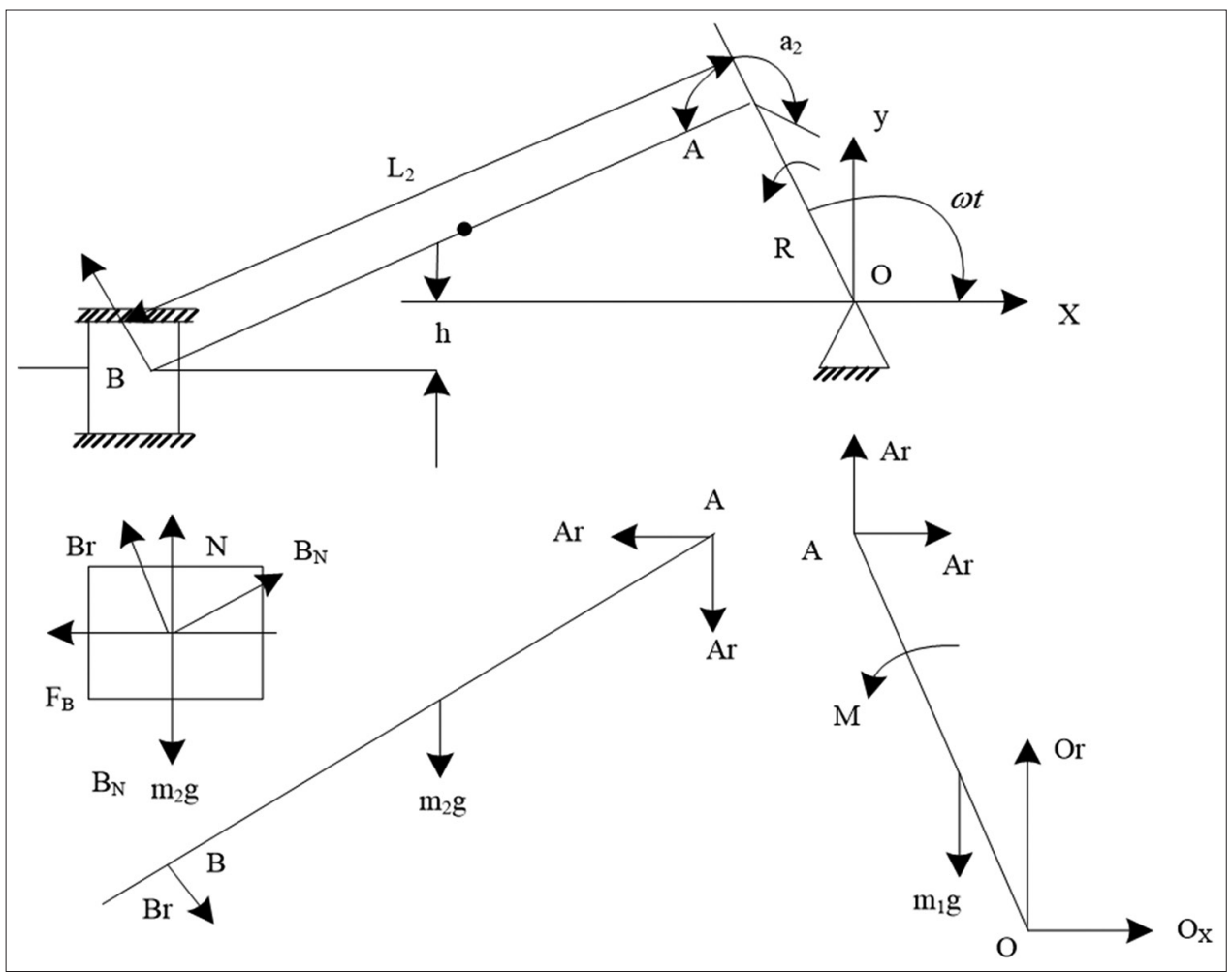

Fig 4. The schematic and stress analysis of the crank cutting mechanism.

$$
\left\{\begin{array}{l}
\ddot{x}_{B}=\ddot{x}_{A}-L_{2}\left(\ddot{a}_{2} \sin a_{2}+\dot{a}_{2} \cos \alpha_{2}\right) \\
\ddot{y}_{B}=\ddot{y}_{A}-L_{2}\left(\ddot{a}_{2} \cos \alpha_{2}-\dot{a}_{2} \sin a_{2}\right)=0
\end{array}\right.
$$

In the same way, we find that:

$$
\left\{\begin{array}{l}
\ddot{x}_{2}=\ddot{x}_{A}-L_{2 a}\left(\ddot{a}_{2} \sin a_{2}+\dot{a}_{2}^{2} \cos \alpha_{2}\right) \\
\ddot{y}_{2}=\ddot{y}_{A}-L_{2 a}\left(\ddot{a}_{2} \cos \alpha_{2}-\dot{a}_{2}^{2} \sin a_{2}\right)
\end{array}\right.
$$

\section{Dynamic analysis of structure}

The force moment of the crank is analyzed, and the coupling moment of the chain link is described by the formula (8):

$$
\left\{\begin{array}{l}
\sum x=o_{x}-m_{1} \ddot{x}_{1}+P \cos \alpha+A_{x}=0 \\
\sum y=o_{y}-m_{1} \ddot{y}_{1}+P \sin \alpha+A_{y}-m_{1} g=0 \\
\sum M_{0}=P_{r}+A_{y} x_{A}-A_{x} y_{A}-m_{1} g x_{1}=0
\end{array}\right.
$$

In the formula, $P$ is the chain force, the unit is $N, r$ is the radius of sprocket circle, and $m$ is the connecting rod as the research object. Then,

$$
\left\{\begin{array}{l}
\sum x=-A_{x}+B_{N} \cos \alpha_{2}+B_{T} \cos \left(\alpha_{2}+\pi / 2\right)-m_{2} \ddot{x}_{2}=0 \\
\sum y=-A_{y}+B_{N} \sin \alpha_{2}+B_{T} \sin \left(\alpha_{2}+\pi / 2\right)-m_{2} \ddot{y}_{2}-m_{2} g=0 \\
\sum M_{A}=B_{T} L_{2}-m_{2}\left(g+\ddot{y}_{A}\right)\left(x_{2}-x_{A}\right)+\ddot{x}_{A} m_{2}\left(y_{2}-y_{A}\right)-J_{2 a} \ddot{\alpha}_{2}=0
\end{array}\right.
$$

In the formula, $\left(x_{2}, y_{2}\right)$ is the centroid coordinate of the connecting rod, and $J_{2 a}$ is the moment of inertia of the point $A$ on the connecting rod.

With the cutting tool as the object, there are:

$$
\left\{\begin{array}{l}
\sum x=-F_{B}+B_{N} \cos \left(\alpha_{2}-\pi\right)+B_{T} \cos \left(\alpha_{2}-\pi / 2\right)-m_{3} \ddot{x}_{B}=0 \\
\sum y=N_{B}-m_{3} g+B_{N} \sin \left(\alpha_{2}-\pi\right)+B_{N} \sin \left(\alpha_{2}-\pi / 2\right)-m_{3} \ddot{y}_{B}=0
\end{array}\right.
$$

In the formula, $F_{B}=N_{B} \tan \varphi$, the direction of $F_{B}$ is determined by $\dot{x}_{B}$ and it is reversed with $\dot{x}_{B}$.

Based on the above kinematics equations, the forces and moments can be obtained (Ye et al., 2015). Using the program to calculate the optimal position and the most reasonable weight, the optimal combination scheme can be obtained, so that the vibration of the harvester is well controlled and the vibration of the cutting structure in crawler-type combine harvester can be solved.

\section{Vibration control method for the engine of crawler- type combine harvester}

There are many reasons for the vibration of the engine in work, such as the periodic movement of the engine center of gravity, the inertia force acting along the cylinder, the centrifugal inertia force of all rotating parts, the 
alternating action of the gas pressure, and the rotation of the crankshaft (Wang et al., 2015). It is often expensive and limited to reduce vibration by changing the structural parameters of the engine system. The easy way to apply the vibration system is to increase the damping of the vibration system (Yang and Upadrashta, 2016). In general, the engine of crawler-type combine harvester is placed horizontally on the whole machine frame by four pivot points. At the joint of the frame bolt, the rubber damping pad is installed to reduce the transmission of engine vibration through the damping effect.

The design of the vibration damping model is based on the theory of vibration science, and the modern design method is fully applied. The vibration model is established by the modal analysis of the body and the finite element calculation, and the parameter of the damping pad is designed and selected reasonably (Rao et al., 2014). The effect of damping on the amplitude of forced vibration is great only in the vicinity of the resonance frequency, but small in the place far away from the resonance frequency, therefore, the vibration characteristics of the system are improved from weakening the excitation source and avoiding resonance. So that, the undamped forced vibration formula can be derived at this time.

According to the conductivity and the formula for the frequency and force relationship of the undamped free vibration in the single degree of freedom system, there are

$$
\begin{aligned}
T & =\frac{1}{\left(\frac{f_{d}}{f_{t}}\right)^{2}-1} \\
f_{n} & =\frac{1}{2 \neq} \sqrt{\frac{k}{m}} \\
F & =k \delta
\end{aligned}
$$

The stiffness and maximum static deformation of the damping pad are deduced.

The stiffness and maximum static deformation of the damping pad are described by formula (14) and (15) respectively.

$$
\begin{aligned}
& k=\frac{4 \pi^{2} f_{d}^{2} m T}{1+T} \\
& \delta=\frac{(1+T) g}{4 \pi^{2} T f_{d}^{2}}
\end{aligned}
$$

In the above formula, $T$ is the conductivity, which is a dimensionless ratio. According to the overseas researches, the vibration isolation effect of $70 \%$ to $90 \%$ can be achieved (Lei and Wen 2015). Under general conditions, $T$ can be valued from 0.1 to 0.3 ; $m$ is the mass of the system, which indicates the mass of the engine here. As the engine weight is shared by four supporting points, the support mass of four points should be calculated according to the position of the center of gravity. $f_{d}$ is the interference frequency or input frequency of the system. Here it is the vibration frequency of the engine. There are different vibration input frequencies at different rotational speeds, and they can be obtained by the formula (16). The vibration frequency of the engine is considered to be its frequency doubling, which is derived from the vertical vibration. $n$ is the engine speed and its unit is $r / \min . f_{n}$ is the natural frequency of the system. This refers to the frequency of the whole system composed of the engine and the damping pad, which can be regarded as the transmission frequency of the damping pad to the outside.

$f_{d}=\frac{2 n}{60}$

Assuming that the engine is rigid, it has six degrees of freedom motion, and each degree of freedom motion has its own frequency and affects each other. For the engine installation system, it can be simplified to six movements without mutual interference, and only affects the damping pad with fixed position. After simplification, the engine represents a unit with mass and moment of inertia. By connecting the rigid rod with the support point, the spring with three directions is fixed on the main engine system, so the finite element method can be used to analyze (Zhao et al., 2007), to further establish the vibration damping model, and to design the appropriate damping cushion parameters, realizing the control of the engine vibration of the crawler-type combine harvester.

\section{Experimental analysis Vibration damping experiment of engine and cutting structure}

In order to verify whether the proposed method can solve the vibration problem of crawler-type combine harvester, this paper carries out experiment on $G$ type combine harvester. The two main vibration sources of the $G$ type combine harvester are the cutting platform vibration and the engine vibration. The cutting platform is located at the front of the harvester and the engine is located in the rear of the harvester. The concrete experiment plan is as follows: firstly, put the ring box at the support seat of the cutting platform; secondly, add the counterweight iron on the main drive shaft of the cutter, and adjust the installation angle of the balance block to be $-10^{\circ}$; thirdly, use the convex concave damping plate at the engine support and adjust the safety position of the gasket to achieve the ideal position (Hasan, 2018) 
The instrument used in the experiment is EDX-1500A type of multi-channel vibration measuring instrument. Under various working conditions, combined with various vibration damping measures, the changes of the strain and acceleration of the frame with high stress and structural strength in the weak parts of the crawler-type combine are measured, including the side wall of the shield, the side of the bridge, the stress of the side wall of the tank and so on. The time history curves of the amplitude variation of the tank side wall before and after vibration damping are described in Fig. 5, and the time history curves of acceleration amplitude of the shield side wall before and after vibration reduction are described in Fig. 6. The graph is analyzed by FFT and the statistical results are described in Table 1 (Islam et al., 2018)

Analysis of Fig. 5 shows that the curves of the amplitude variation of the tank side wall before and after damping are obvious. Fig. 5 (a) shows that the time history curve of the strain amplitude before vibration damping is fluctuating from -1000 to 1000 , the amplitude of the fluctuation is different, and the amplitude of the strain is extremely unstable. It shows that the engine and cutting structure produce a large amplitude vibration during the operation of crawler-type combine harvester, and to be conducted to the frame, making the strong vibration sense in machine. Fig. 5 (b) shows that the time history curve of the strain amplitude value by using the proposed method is slightly fluctuated in $0 \sim 1000$, and the amplitude of the fluctuation is relatively neat and stable. It shows that the vibration problem of the engine and cutting structure of the crawlertype combine harvester is obviously improved after the vibration damping is adopted by the proposed method, so the vibration of the frame is small, and the vibration feeling experienced by the machine during operation is obviously reduced (Mahmud et al., 2018)

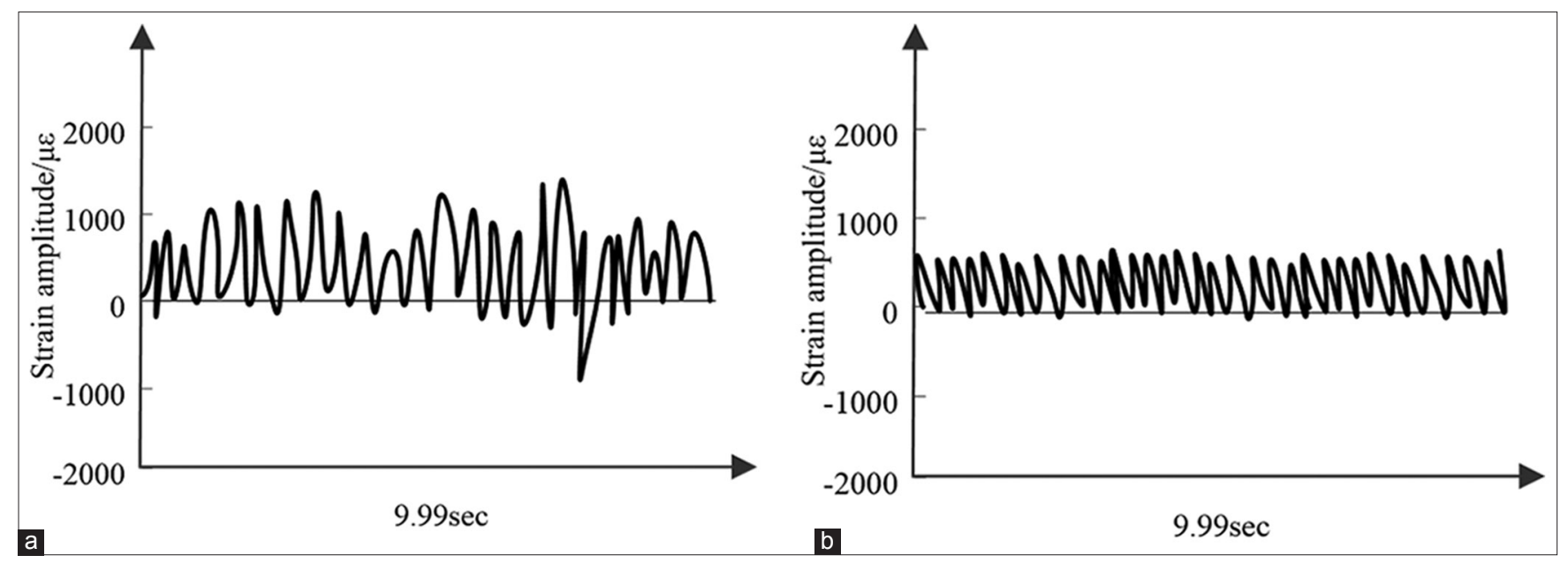

Fig 5. Comparison of time history curves of amplitude and amplitude before and after vibration reduction of tank side walls. (a)Time history curve of strain amplitude value before vibration damping of oil tank (b) Time history curve of strain amplitude value after vibration damping of oil tank.

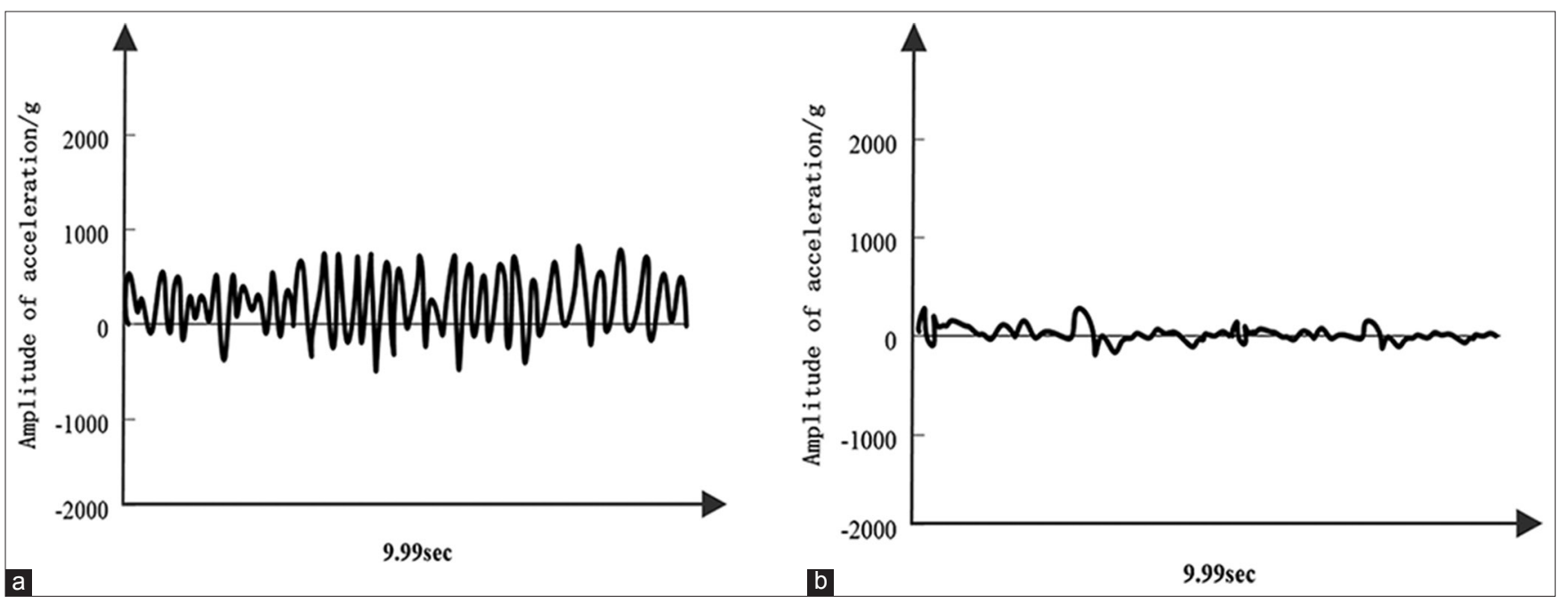

Fig 6. Comparison of the time history curves between the amplitude and amplitude of the side wall of the cutting platform shield before and after vibration damping. (a)Time history curve of acceleration amplitude before damping of side wall of header. (b)Time history curve of acceleration amplitude after damping of side wall of header. 
Compared with the damping effect of the side wall of the fuel tank, the damping effect of the side wall of the cutting platform shield is more convincing. Analysis of Fig. 6 shows that before and after the vibration damping of the side wall of the cutting platform shield, the time history curves of the acceleration amplitude are comparable. Before the vibration damping, the curve fluctuates from -500 to 1000 , and the amplitude of the fluctuation is unevenly distributed. The unstable amplitude of acceleration shows that the engine and the cutting structure generate large amplitude vibration and transmit it to the cutting platform shield, during the operation of crawler-type combine harvester, resulting in the corresponding vibration of the cutting platform shield, and causing the machine to generate strong vibration. From Fig. 6 (b), it can be seen that the acceleration amplitude of the side wall of the cutting platform shield is only small in the range of -200 to 300 and tends to a steady state in the middle. It shows that the vibration condition of the crawler-type combine harvester is obviously improved after this method is adopted, so the vibration of the frame is smaller, and the vibration of the machine is weak during the operation.

In the analysis table 1, the maximum strain of the tank is 240.08 before variation dumping, and the maximum strain after vibration damping by using the proposed method is 77.117 , reduced by $67.88 \%$. The mean value and standard deviation of strain of the tank's side wall are reduced by $71.69 \%$ and $42.22 \%$, respectively. At the left end of the bridge, the maximum strain before variation dumping is 326.2 , and that after vibration damping by using the proposed method is 136.3 , decreased by $58.22 \%$. The mean value and standard deviation of strain at the left end of the bridge are reduced by $84.8 \%$ and $86.16 \%$ respectively. At the right end of the bridge, the maximum strain is 212.93 , and that after vibration damping by using the proposed method is 123.9, decreased by $41.78 \%$. mean value and standard deviation of strain at the right end of the bridge are reduced by $56.3 \%$ and $86.72 \%$, respectively. The maximum value of acceleration before vibration damping is 1.2054, and that after vibration damping by using the proposed method is 0.591 , decreased by $50.97 \%$. The mean value and standard deviation of average acceleration at the left wall of the cover shield is reduced by $53.6 \%$ and $76.3 \%$ respectively. The above data show that the vibration effect of the side wall of the tank, the left and right side of the bridge and the left wall of the cover shield are greatly reduced by using the proposed method, the vibration degree is obviously improved, and the feasibility and effectiveness of the method are verified.

\section{Engine's vibration damping experiment}

In order to verify whether the vibration control method of the crawler-type combine harvester proposed in this paper is superior to the traditional control method, the vibration comparison test of the crawler-type combine

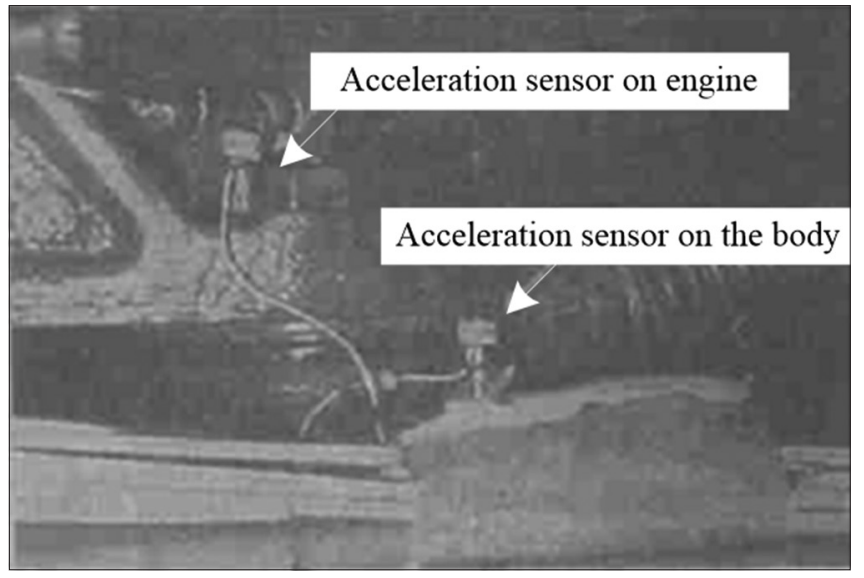

Fig 7. Engine acceleration sensor test installation diagram.

Table 1: Comparison of damping test results of crawler combine harvester

\begin{tabular}{|c|c|c|c|}
\hline & Pre vibration & After vibration damping & Vibration reduction $/ \%$ \\
\hline \multicolumn{4}{|l|}{ Side wall of oil tank } \\
\hline Maximum strain $(\mu \varepsilon)$ & 240.08 & 77.117 & 67.88 \\
\hline Strain averages $(\mu \varepsilon)$ & 91.62 & 25.93 & 71.69 \\
\hline Strain standard deviation $(\mu \varepsilon)$ & 42.109 & 24.33 & 42.22 \\
\hline \multicolumn{4}{|l|}{ The left end of the bridge } \\
\hline Maximum strain $(\mu \varepsilon)$ & 326.2 & 136.3 & 58.22 \\
\hline Strain averages $(\mu \varepsilon)$ & 32.859 & 4.99 & 84.8 \\
\hline Strain standard deviation $(\mu \varepsilon)$ & 78.741 & 10.89 & 86.16 \\
\hline \multicolumn{4}{|l|}{ Right end of the bridge } \\
\hline Maximum strain $(\mu \varepsilon)$ & 212.93 & 123.9 & 41.78 \\
\hline Strain averages $(\mu \varepsilon)$ & 26.6038 & 11.61 & 56.3 \\
\hline Strain standard deviation $(\mu \varepsilon)$ & 51.765 & 6.874 & 86.72 \\
\hline \multicolumn{4}{|l|}{ The left wall of the shroud } \\
\hline Maximum acceleration $(g)$ & 1.2054 & 0.591 & 50.97 \\
\hline Mean value of acceleration $(g)$ & 0.0097 & 0.0045 & 53.6 \\
\hline Standard deviation of acceleration (g) & 0.2887 & 0.068 & 76.3 \\
\hline
\end{tabular}


Table 2: a value and T value of the original damping pad at the engine system $\left(\mathrm{g}=9.81 \mathrm{~m} / \mathrm{s}^{2}\right)$

\begin{tabular}{|c|c|c|c|c|c|c|}
\hline \multirow[t]{2}{*}{ Damping pad position } & \multicolumn{2}{|c|}{$\begin{array}{c}\text { Idling } \\
\text { (846r/min) }\end{array}$} & \multicolumn{2}{|c|}{$\begin{array}{l}\text { Medium speed } \\
\text { transport } \\
(1524 \mathrm{r} / \mathrm{min})\end{array}$} & \multicolumn{2}{|c|}{$\begin{array}{l}\text { High speed } \\
\text { operation } \\
(2121 \mathrm{r} / \mathrm{min})\end{array}$} \\
\hline & $a$ & $T / \%$ & $a$ & $T / \%$ & $a$ & $T / \%$ \\
\hline Damper pad position engine right front side & $0.56 \mathrm{~g}$ & 54 & $1.14 \mathrm{~g}$ & 52 & $2.11 \mathrm{~g}$ & 63 \\
\hline Right front side of the frame & $0.30 \mathrm{~g}$ & & $0.59 \mathrm{~g}$ & & $1.33 \mathrm{~g}$ & \\
\hline Left rear side of engine & $0.72 \mathrm{~g}$ & 46 & $0.94 \mathrm{~g}$ & 85 & $1.45 \mathrm{~g}$ & 96 \\
\hline Left rear side of frame & $0.33 \mathrm{~g}$ & & $0.80 \mathrm{~g}$ & & $1.39 \mathrm{~g}$ & \\
\hline
\end{tabular}

Table 3: a value and $T$ value of the new damping pad at the engine system $(g=9.81 \mathrm{~m} / \mathrm{s} 2)$

\begin{tabular}{|c|c|c|c|c|c|c|}
\hline \multirow[t]{2}{*}{ Damping pad position } & \multicolumn{2}{|c|}{$\begin{array}{c}\text { Idling } \\
\text { (922r/min) }\end{array}$} & \multicolumn{2}{|c|}{$\begin{array}{l}\text { Medium speed transport } \\
(1536 \mathrm{r} / \mathrm{min})\end{array}$} & \multicolumn{2}{|c|}{$\begin{array}{l}\text { High speed operation } \\
(2142 \mathrm{r} / \mathrm{min})\end{array}$} \\
\hline & $a$ & $T / \%$ & $a$ & false $/ \%$ & $a$ & $T / \%$ \\
\hline Right front side of the engine & $0.53 \mathrm{~g}$ & 24 & $1.36 \mathrm{~g}$ & 8 & $1.04 \mathrm{~g}$ & 8 \\
\hline Right front side of the frame & $0.18 \mathrm{~g}$ & & $0.11 \mathrm{~g}$ & & $0.32 \mathrm{~g}$ & \\
\hline Left rear side of engine & $0.29 \mathrm{~g}$ & 31 & $0.66 \mathrm{~g}$ & 20 & $1.37 \mathrm{~g}$ & 16 \\
\hline Left rear side of frame & $0.12 \mathrm{~g}$ & & $0.13 g$ & & $0.21 \mathrm{~g}$ & \\
\hline
\end{tabular}

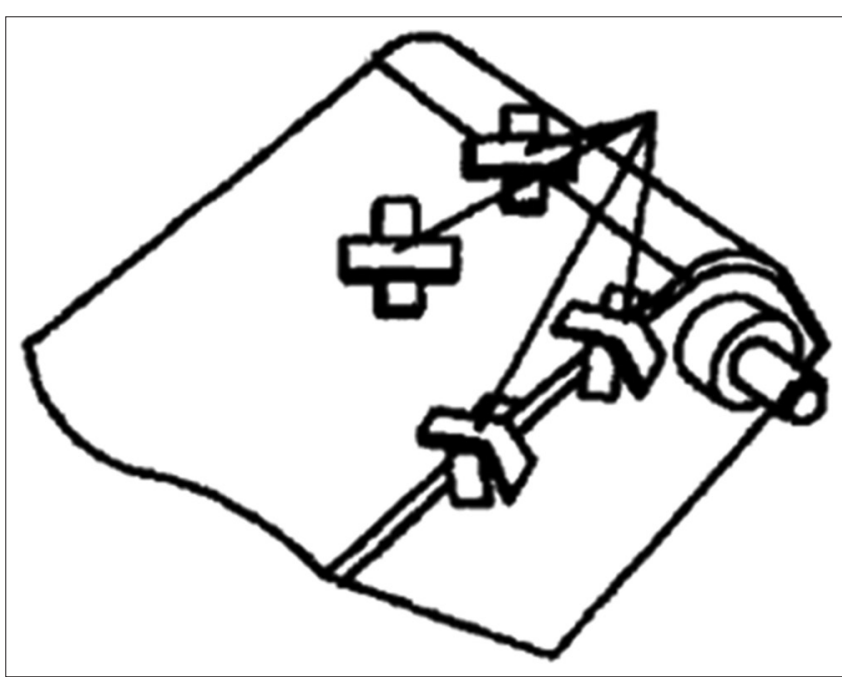

Fig 8. Stickup position of strain gauge.

harvester is carried out. The main method is to install an acceleration sensor on the engine support base of the harvester and the supporting end of the engine, as shown in Fig. 7.In the experiment, the vibration of the whole machine and the parts affected by vibration are selected as measuring points, and strain gauges are installed as shown in Fig. 8.By analyzing the vibration acceleration $a$ and strain condition of different parts under different rotating speed conditions, the influence of engine's vibration source on the working state of the whole machine is determined.

The conductivity $T$ of vibration is shown in Table 2 and Table 3. The greater the value is, the greater the vibration received by the rack is, and vice versa. Analysis of Table 2 and Table 3 show that different shock absorbers have different effects on vibration isolation of crawler-type combine harvesters. At the stage of idling, the acceleration values of the right front side of the engine, the right front of the frame, the left rear side of the engine and the left rear side of the engine are $0.56 \mathrm{~g}, 0.30 \mathrm{~g}, 0.72 \mathrm{~g}$ and $0.33 \mathrm{~g}$ respectively, when the harvester adopts the original damping pad to reduce vibration. The vibration conductivities of the right front side of the engine and the left rear side of the engine are 54 and 46, respectively. The acceleration values of the right front side of the engine, the right front side of the frame, the left rear side of the engine and the left rear side of the engine are $0.53 \mathrm{~g}, 0.18 \mathrm{~g}, 0.29 \mathrm{~g}$ and $0.12 \mathrm{~g}$ respectively after using the new dumping pad proposed in the method of this paper. The vibration conductivities of the right front side of the engine and the left rear side of the engine are 24 and 31 respectively. The above two sets of data indicate that the damping effect obtained by adopting the new damping pad is not obvious. The main reason is that at the stage of idling, the vibration of harvester is small, so the effect of vibration dumping is little.

At the stage of medium speed operation, by using the original damping pad to reduce vibration, the acceleration values of the right front side of the engine, the right front side of the frame, the left rear side of the engine and the left rear side of the engine are $1.14 \mathrm{~g}, 0.59 \mathrm{~g}, 0.94 \mathrm{~g}$ and $0.80 \mathrm{~g}$ respectively, and the vibration conductivities of the right front side of the engine and the left rear side of the engine are 52 and 85 respectively; after using the new dumping pad proposed in this paper, the acceleration values of those are $1.36 \mathrm{~g}, 0.11 \mathrm{~g}, 0.66 \mathrm{~g}$ and $0.13 \mathrm{~g}$ respectively, and the vibration conductivities of the right front side of the engine and the left rear side of the engine are 8 and 20, respectively. The above two sets of data indicate that the vibration damping effect obtained by adopting the new damping pad is obvious. Because in the stage of middle speed operation, the vibration generated by the harvester is relatively large, the damping pad can give full play to its damping function and improve the vibration influence of the rack. 
Table 4: Stress level of parts at vulnerable parts

\begin{tabular}{|c|c|c|c|}
\hline Installation of strain gauge position & $\begin{array}{l}\text { Original damping } \\
\text { cushion }\end{array}$ & $\begin{array}{l}\text { New damping } \\
\text { pad }\end{array}$ & $\begin{array}{l}\text { The new damping pad } \\
\text { reduces the percentage/\% }\end{array}$ \\
\hline The upper part of the left screen box drive hole position & 45.3 & 26.6 & 41.3 \\
\hline The lower part of the left sieving box drive hole position & 49.7 & 28.2 & 43.1 \\
\hline $\begin{array}{l}\text { The upper part of the right side of the sieving box on the } \\
\text { right side }\end{array}$ & 27.7 & 14.1 & 49.0 \\
\hline Right sieve box drive hole position behind the lower part & 43.4 & 24 & 44.7 \\
\hline The upper part of the drive axle of the bridge & 39.7 & 20 & 49.6 \\
\hline
\end{tabular}

At the stage of high speed operation, the acceleration values of the right front side of the engine, the right front side of the frame, the left rear side of the engine and the left rear side of the engine are $2.11 \mathrm{~g}, 1.33 \mathrm{~g}, 1.45 \mathrm{~g}$ and $1.39 \mathrm{~g}$ respectively, when the harvester adopts the original damping pad to reduce vibration. The vibration conductivities of the right front side of the engine and the left rear side of the engine are 63 and 96, respectively. While after using the new dumping pad proposed in this paper, the acceleration values of those are $1.04 \mathrm{~g}, 0.32 \mathrm{~g}, 1.37 \mathrm{G}$ and $0.21 \mathrm{~g}$ respectively, and the vibration conductivities of the right front side of the engine and the left rear side of the engine are 8 and 16, respectively. The above two sets of data show that the vibration damping effect obtained by the new damping pad is very obvious, the conductivities of the right front side of the engine and the left side of the engine is reduced by about $87.3 \%$ and $83.33 \%$ respectively, and the vibration acceleration of each part is greatly reduced. Because during the high-speed operation stage, the vibration generated by the harvester is very strong, the damping pad can fully exert its damping function and improve the vibration influence of the rack.

In the analysis Table 4, it can be seen that the stress level of the parts in the five different positions of the strain gauge is obviously reduced after using the new damping pad, and all are above $40 \%$.

The experimental results show that by using the method of this paper to control the vibration, the crawler-type combine harvester does not resonate with the host in the working speed range. Under normal operation in the field, the vibration level of the harvester is $50 \%$ to $80 \%$ lower than that of the original, and the stress level of the vulnerable parts is reduced by about $40 \%$, indicating that the vibration of a crawler-type combine harvester can be effectively improved.

\section{CONCLUSION}

In this paper, the vibration control method of the crawlertype combine harvester is put forward to analyze the dynamics and vibration, obtain the best position and the mass of counterweight, establish the vibration damping model and design the parameters of the dumping pad. It can effectively solve the vibration problem of the harvester. Compared with the traditional method, the effect of the proposed method is obvious, providing effective means to solve vibration problems of crawler-type combine harvester, and it has high practical application value.

\section{ACKNOWLEDGEMENT}

Research on key technology of walking system of whole-feeding crawler combine harvester (No. 20180432B37).

\section{REFERENCES}

Ahamed, A. J., K. Loganathan, S. Ananthakrishnan, J. Ahmed and M. A. Ashraf. 2017. Evaluation of graphical and multivariate statistical methods for classification and evaluation of groundwater in alathur block, Perambalur District, India. Appl. Ecol. Environ. Res. 15(3): 105-116.

Amereh, M., M. Haghighi and P. Estifaee. 2018. The potential use of hno3-treated clinoptilolite in the preparation of $\mathrm{pt} / \mathrm{ceo} 2$ clinoptilolite nanostructured catalyst used in toluene abatement from waste gas stream at low temperature. Arabian J. Chem. 11(1): 81-90.

Amponsah, S. K., A. Addo and K. A. Dzisi. 2017. Performance evaluation and field characterization of the sifang mini rice combine harvester. Appl. Eng. Agric. 33(4): 44-49.

Islam M. A., M. Moniruzzaman and M. S. Islam, 2018. Vendors and consumers status and microbiological analysis of some common fast food items of different fast food restaurants in Barisal city. Malays. J. Halal Res. 1(1): 17-21

Chen, J., G. Yang and P. Wu. 2017. Fuzzy control strategy for the forward speed of a combine harvester based on KDD. Appl. Eng. Agric. 33(1): 15-22.

Daya, B. and K. Pant. 2017. Biomonitoring of wetland using macrophytes and macroinvertebrates. Malays. J. Sustain. Agric. 1(1): 11-14.

Dong, Z., F. Wang and Q. Song. 2017. Performance optimization of combine harvester inertia separation chamber based on BPNN. Int. Agric. Eng. J. 26(3): 19-26.

Dorzhiev, V., A. Karami and P. Basset. 2015. Electret-free micromachined silicon electrostatic vibration energy harvester with the bennet's doubler as conditioning circuit. IEEE Electron Device Lett. 36(2): 183-185.

Gafforelli, G., A. Corigliano and R. Xu. 2014. Experimental verification of a bridge-shaped, nonlinear vibration energy harvester. Appl. Phys. Lett. 105(20): 16.

Garcia, A., A. M., A. Gomez-Alvarez, I. Anduro-Corona, A. 
Burgos-Hernandez, E. Ruiz-Bustos, R. Canett-Romero and H. F. Astiazaran-Garcia. 2017. Optimization of the ideal analytical conditions for quantifying aluminum in sprague dawley rats using the atomic absorption technique. Rev. Int. Contam. Ambient. 33(S I): 77-84.

Ghaderi, E., A. Maleki and I. Dianat. 2014. Design of combine harvester seat based on anthropometric data of Iranian operators. Int. J. Ind. Ergon. 44(6): 810-816.

Halim, M. A. and J. Y. Park. 2014. A non-resonant, frequency upconverted electromagnetic energy harvester from human-bodyinduced vibration for hand-held smart system applications. J. Appl. Phys. 115(9): 1457.

Hasan, M. M. 2018. Bioaugmentation approach in rhizospheric microbiome research: A lesson from arsenic remediation. Malays. J. Halal Res. 1(1): 15-16.

Islam, M. N., S. Biswas, M. E. Uddin, A. Shila, M. Z. Haque and N. Mahmud. 2018. Salt tolerance of chili genotypes during germination and seedling growth. Malays. J. Halal Res. 1(2): 1-7.

Jun, H. I., N. L. Kim and J. H. Lim. 2014. Generating characteristics of a cross-shaped piezoelectric energy harvester. Ferroelectrics. 466(1): 92-102.

Krauklis, A. E. and I. Dreyer. 2018. A simplistic preliminary assessment of ginstling-brounstein model for solid spherical particles in the context of a diffusion-controlled synthesis. Open Chem. 16(1): 64-72.

Lei, Y. M. and Z. Wen. 2015. Study on effects of the damping ratio on output performance of micro electromagnetic vibration energy harvesters. Microsyst. Technol. 21(1): 221-226.

Li, H. T., W. Y. Qin and Z. Y. Zhou. 2014. Coherence resonance of piezoelectric energy harvester with fractional damping. Acta Physica Sin. 63(22): 220504-220504.

Litak, G., M. I. Friswell and S. Adhikari. 2016. Regular and chaotic vibration in a piezoelectric energy harvester. Meccanica. 51(5): 1017-1025.

Lee, B. B., G. P. Tan and S. Maniam. 2017. Capacity of black soldier fly and house fly larvae in treating the wasted rice in Malaysia. Malays. J. Sustain. Agric. 1(1): 8-10.

Polin, J. P., Z. Gu and D. S. Humburg. 2014. Source of airborne sunflower dust generated during combine harvester operation. Biosyst. Eng. 126(126): 23-29.

Rafiee, E., A. Shahbazirad and M. Khodayari. 2017. Preparation and characterization of nanocomposite of graphitic carbon nitride and tio2 as a porous support for nano catalyst for desulfurization process. J. Saudi Chem. Soc. 21(8): 943-953.

Rao, T. V. H., M. S. S. Rao and B. V. Apparao. 2014. A study on design and analysis of hybrid vibration damper with energy harvesting and optimal damping effect. J. Inst. Eng. 95(2): 97-102.
Roy, S., G. Handique, F. R. Bora and A. Rahman. 2018. Evaluation of certain non-conventional plant based oils against red spider mite of tea. J. Environ. Biol. 39(1): 1-4.

Sandhu, A. K., M. G. Miller, N. Thangthaeng, T. M. Scott, B. ShukittHale, I. Edirisinghea and B. Burton-Freeman. 2018. Metabolic fate of strawberry polyphenols after chronic intake in healthy older adults. Food Funct. 9(1): 96-106.

Sautrot-Ba, P., J. Malval, M. Weiss-Maurin, J. Paul, A. BlachaGrzechnik, S. Tomane, P. E. Mazeran, J. Lalevee, V. Langlois and D. L. Versace. 2018. Paprika, gallic acid, and visible light: The green combination for the synthesis of biocide coatings. ACS Sustain. Chem. Eng. 6(1): 104-109.

Shen, Y., W. Mi and Z. Zhang. 2017. A positioning lockholes of container corner castings method based on image recognition. Pol. Marit. Res. 24(S I): 95-101.

Sun, Z., L. Wang and Z. Pan. 2014. Analyses of vibration characteristics of power fan for the $4 \mathrm{ztl}-1800$ pneumatic conveying combine stripper harvester. Trans. ASABE. 57(3): 693-699.

Tang, X., T. Lin and L. Zuo. 2014. Design and optimization of a tubular linear electromagnetic vibration energy harvester. IEEE/ASME Trans. Mechatron. 19(2): 615-622.

Tang, Z., Y. Li and L. Xu. 2014. Design and optimization for length of longitudinal-flow threshing cylinder of combine harvester. Nongye Gongcheng Xuebao/Trans. Chin. Soc. Agric. Eng. 30(23): 28-34.

Troujeni, M. E., M. Khojastehpour, A. Vahedi and B. Emadi. 2018. Sensitivity analysis of energy inputs and economic evaluation of pomegranate production in Iran. Inf. Process. Agric. 5(1): 114-123.

Wang, Y. J., C. D. Chen and C. C. Lin. 2015. A nonlinear suspended energy harvester for a tire pressure monitoring system. Micromachines. 6(3): 312-327.

Xie, Y., S. Ge, S. Jiang, Z. Liu, L. Chen, L. Wang, J. Chen, L. Qin and W. Peng. 2018. Study on biomolecules in extractives of Camellia oleifera fruit shell by Gc-Ms. Saudi J. Biol. Sci. 25(2): 234-236.

Yang, Y. and D. Upadrashta. 2016. Modeling of geometric, material and damping nonlinearities in piezoelectric energy harvesters. Nonlin. Dyn. 84(4): 2487-2504.

Ye, Z., L. Su and K. Takahata. 2015. FEA analysis and working performance of micro vibration energy harvester based on diamagnetic levitation. Microsyst. Technol. 21(4): 903-909.

Zhang, N., C. Zhou, W. Xia and A. V. Nguyen. 2018. Volatilization of mercury in coal during conventional and microwave drying and its potential guidance for environmental protection. J. Clean. Prod. 176: 1-6.

Zhao, J. P., W. Q. Yin and A. Y. Huang. 2007. Movement simulation and optimization of grain cleaning sieve of combine harvester. Comput. Simul. 24(11): 185-189. 